\title{
PEMBERDAYAAN MASYARAKAT TERHADAP PENGELOLAAN LIMBAH RUMAH TANGGA DALAM RANGKA MEWUJUDKAN PENINGKATAN KESEHATAN LINGKUNGAN DAN PEREKONOMIAN DI DESA KURIPAN
}

\author{
M. Dahlan $\mathrm{R}^{1}$, Unang Setiana, Muhammad Kosasih ${ }^{2}$ \\ dahlan@fai.uika-bogor.ac.id \\ Dosen Fakultas Agama Islam¹, Mahasiswa KKN Kelompok 34 Tahun $2017^{2}$
}

\begin{abstract}
ABSTRAK
Manusia berinteraksi dengan lingkungan terus-menerus. Interaksi ini mempengaruhi kualitas hidup, tahun hidup sehat hidup, dan kesenjangan kesehatan. Kesehatan lingkungan merupakan faktor penting dalam kehidupan sosial kemasyarakatan, bahkan merupakan salah satu unsur penentu atau determinan dalam kesejahteraan penduduk. Di mana lingkungan yang sehat sangat dibutuhkan bukan hanya untuk meningkatkan derajat kesehatan masyarakat, tetapi juga untuk kenyamanan hidup dan meningkatkan efisiensi kerja dan belajar. Salah satu implementasi dari kesehatan lingkungan adalah dengan menjaga kebersihan dari sampahsampah baik organic maupun an organic. Sampah anorganik biasanya berupa botol, kertas, plastik, kaleng, sampah bekas alat- alat elektronik dan lain-lain. Sampah ini sering kita jumpai di beberapa tempat seperti sungai, halaman rumah, lahan pertanian dan di jalan-jalan. Sifatnya sukar diurai oleh mikroorganisma, sehingga akan bertahan lama menjadi sampah. Sampah plastik bisa bertahan sampai ratusan tahun, sehingga dampaknya akan sangat lama. Masalah sampah merupakan masalah masyarakat secara keseluruhan karena setiap hari sampah selalu ada. Tidak terkecuali dengan Desa Kuripan, tepatnya di dusun Cihoe Ombang. Salah satu problem yang terjadi adalah berserakan sampah di sekitar pemukiman warga. Maka dari itu, perlu adanya upaya untuk mengatasi problem tersebut, yaitu dengan memberdayakan masyarakat dalam pengelolaan limbah an organik untuk meningkatkan kesehatan lingkungan dan perekonomian.
\end{abstract}

Kata Kunci : Kesehatan, Limbah, Lingkungan, Perekonomian.

\section{PENDAHULUAN}

Dusun Cihowe Ombang merupakan salah Dusun di Desa Kuripan, Kecamatan Ciseeng, Kabupaten Bogor. Dusun Cihowe Ombang berbatasan langsung dengan dusun dan desa yang lain di sekitarnya, yakni sebelah utara Dusun Gunung Sindur, sebelah Selatan Desa Cihoe, Sebelah barat Dusun Gunung Calincing dan Sebelah timur dengan Desa Cogreg
Sebagian besar penduduk Cihowe berprofesi sebagai Peternak ayam dan Ikan. Hal itu sesuai dengan keadaan yang ada wilayahnya tersebut yaitu banyak terdapat lahan yang luas untuk dijadikan kandang ayam dan kolam ikan. Jumlah warga di kampung Cihoe Ombang ini ada sekitar 700 orang yang terdiri dari 320 kepala keluarga, yang terbagi atas empat RT dan Satu RW yaitu RT 1, 2, 3 dan 4 dan RW 4. 
Organisasi manyarakat di Desa Kuripan antara lain RT, RW, paguyuban ronda, PKK, kelompok ternak dan Karang taruna (organisasi kepemudaan). Sedangkan sebagian masyarakatnya menganut agama Islam.

Terdapat berbagai permasalahan pokok di Dusun Cihowe Ombang ini yang perlu mendapat perhatian maupun bantuan agar masalah-masalah tersebut dapat diatasi demi mewujudkan desa yang mandiri dan memiliki daya saing yang tinggi.

\section{Keadaan Geografis}

Desa Kuripan memiliki luas wilayah 511,6Ha. Dengan batas wilayahnya adalah sebagai berikut:

\begin{tabular}{|c|l|c|}
\hline No & Keterangan & Berbatasan \\
\hline 1 & Utara & $\begin{array}{c}\text { Desa Jampang, Kec. } \\
\text { Gunung Sidur }\end{array}$ \\
\hline 2 & Selatan & $\begin{array}{c}\text { Desa Cibentang dan } \\
\text { Cibeteung Muara }\end{array}$ \\
\hline 3 & Barat & $\begin{array}{c}\text { Kali Cisadane Kec. } \\
\text { Rumpin }\end{array}$ \\
\hline 4 & Timur & $\begin{array}{c}\text { Desa Cogreg Kec } \\
\text { Parung dan Cihoe }\end{array}$ \\
\hline
\end{tabular}

\section{Jumlah Penduduk}

\begin{tabular}{|c|l|c|}
\hline No & Jenis Kelamin & Jumlah \\
\hline 1 & Laki-Laki & 5.021 \\
\hline 2 & Perempuan & 4.794 \\
\hline 3 & Kepala Keluarga & 3.180 \\
\hline
\end{tabular}

RW 04 terdiri dari empat RT, Sebagian Besar Masyarakat RW 04 Bermata Pencaharian sebagai Peternak Ayam dan juga Budidaya Ikan Lele.
Permasalahan sumber air terdapat di RT 01, 02, 03. Untuk RT 04 ada beberapa sumber air yang berasal dari sumur. Satu sumur bisa untuk 3 rumah dan tidak ada tempat penyimpanan air sehingga setiap membutuhkan air harus menyalakan pompaan listrik. Rata-rata di setiap rumah belum tersedia septitank yang baik, untuk pembuangan akhir limbah rumah tangga (Kotoran) hanya dilubang terbuka berisi air hijau dan sewaktu-waktu ketika penuh air tersebut itu akan meluap keluar. Dan tidak tersedianya tempat Pembuangan Akhir Sampah, sehingga masyarakat membakar sampah tersebut. Masyarakat RT 04/04 terdapat dua golongan yaitu golongan anti speaker dan yang tidak anti speaker. Peran Tokoh masyarakat sangat penting agar tidak menimbulkan pertengkaran dan terjalin kerukunan antar warga.

\section{Pendidikan}

\begin{tabular}{|c|l|c|}
\hline No & Tingkat Pendidikan & Jumlah \\
\hline 1 & SD & 1.286 \\
\hline 2 & SMP & 988 \\
\hline 3 & SMA & 798 \\
\hline 4 & Tidak Sekolah & 60 \\
\hline \multicolumn{2}{|c|}{ Masih kurangnya fasilitas bagi }
\end{tabular}
pendidikan di Desa Kuripan, serta kurangnya tingkat kesadaran dari orang tua akan pentingnya pendidikan terhadap anak-anak mereka, dan juga kurangnya tenaga pengajar. 


\section{METODE PENGABDIAN}

Tahapan pelaksanaan pada kegiatan ini, dapat dilihat pada bagan dibawah ini:

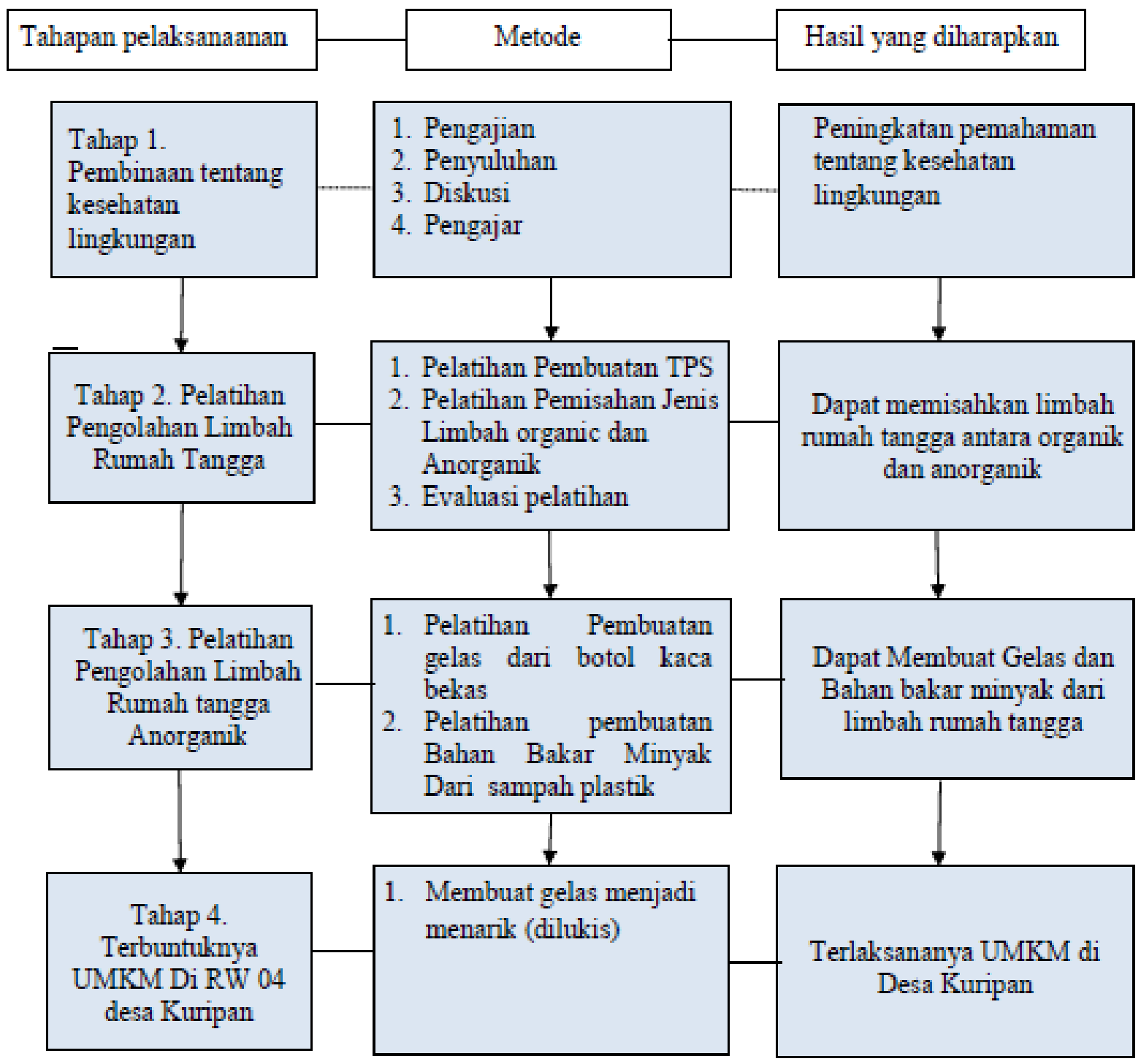


Jadwal Kegiatan

\begin{tabular}{|c|c|c|c|c|c|c|c|c|c|}
\hline \multirow{2}{*}{ No. } & \multirow{2}{*}{ Kegiatan } & \multicolumn{4}{|c|}{ Agustus } & \multicolumn{4}{|c|}{ September } \\
\hline & & 1 & 2 & 3 & 4 & 1 & 2 & 3 & 4 \\
\hline 1 & Penyusunan Rencana kegiatan & & & & & & & & \\
\hline 2 & Sosialisasi rencana kegiatan & & & & & & & & \\
\hline 3 & $\begin{array}{l}\text { Pembinaan tentang Perilaku Hidup } \\
\text { Bersih Sehat }\end{array}$ & & & & & & & & \\
\hline 4 & $\begin{array}{l}\text { Pelatihan Pembuatan Produk makanan } \\
\text { dari daun singkong }\end{array}$ & & & & & & & & \\
\hline 5 & Pembuatan Tempat sampah dari Bambu & & & & & & & & \\
\hline 6 & $\begin{array}{l}\text { Pemisahan Sampah Organik dan } \\
\text { Anorganik }\end{array}$ & & & & & & & & \\
\hline 7 & Pembelian peralatan Pengolahan Limbah & & & & & & & & \\
\hline 8 & $\begin{array}{l}\text { Penyuluhan tentang Pengelolaan limbah } \\
\text { anorganik secara pandangan hukum } \\
\text { negara, keagamaan, ekonomi, kesehatan } \\
\text { dan teknologi tepat guna. }\end{array}$ & & & & & & & & \\
\hline 9 & $\begin{array}{l}\text { Pelatihan membuat gelas dari botol kaca } \\
\text { bekas }\end{array}$ & & & & & & & & \\
\hline 10 & $\begin{array}{l}\text { Pelatihan membuat bahan bakar minyak } \\
\text { dari sampah plastic }\end{array}$ & & & & & & & & \\
\hline 11 & $\begin{array}{l}\text { Pemberian Alat Pengolahan Limbah } \\
\text { Kepada Masyarakat }\end{array}$ & & & & & & & & \\
\hline 12 & Monitoring dan evaluasi & & & & & & & & \\
\hline 13 & Penyusunan laporan & & & & & & & & \\
\hline
\end{tabular}

\section{Metode Pendekatan}

Pendekatan yang digunakan dalam kegiatan ini adalah:

1) Pendekatan religius, yaitu pendekatan yang menggunakan nilai-nilai agama sebagai basis kegiatan. Pendekatan ini sangat penting karena permasalahan pemahaman radikalisme dalam masyarakat sangat dipengaruhi oleh faktor keimanan, pengalaman keagamaan, rasa tanggungjawab dan pengetahuan (Rachmawati, 2010).

2) Pendekatan organisasi, yaitu pendekatan dimana seluruh kegiatan diorganisir oleh pemuda di RT 04/04. Hal ini sesuai dengan hasil penelitian Bahari (2010) dimana dia menemukan bahwa keterlibatan organisasi mempunyai pengaruh langsung terhadap toleransi. Pendekatan kepada pemuda lebih dikhususkan karena pemuda merupakan kader penerus perjuangan bangsa dan pembangunan nasional.1

3) Pendekatan kekerabatan, artinya bahwa pembinaan yang dilakukan senantiasa dikaitkan dalam rangka membangun kekerabatan antar warga sekitar, guruguru dan murid di SD, guru dan murid di TPA

4) Pendekatan berdasarkan karakter masyarakat, yakni pembinaan yang dilakukan akan disesuaikan dengan 
karakter masyarakat. Joyce dan Weil (1996) mengungkapkan bahwa model pendidikan yang relevan dengan perilaku sosial dan nilai adalah dengan banyak memberikan permainan peran. Hal ini dilakukan untuk memberi pengalaman riil kepada peserta didik tentang sesuatu yang dilakukan atau dirasakan oleh orang lain. Memang, dalam prakteknya, tidak seluruh aspek harus menggunakan permainan ini. Dalam beberapa hal, terdapat kegiatankegiatan yang hanya golongan tertentu untuk melakukannya. Sejalan dengan konsep Joyce dan Weil, cooperative learning yang digagas Slavin (2005) dapat digunakan untuk membangun kesadaran masyarakat akan pentingnya kerjasama antar masyarakat, sesuai dengan karakter masyarakat Desa Kuripan khususnya di RW 04 yang ratarata warganya adalah petani dan peternak.

\section{Partisipasi Masyarakat dalam Pelaksanaan Program}

Partisipasi masyarakat yang dilakukan dalam kegiatan ini adalah sebagai berikut:

1. Mempersiapkan Masyarakat yang bersedia mengikuti pembinaan baik tentang Perilaku Hidup Bersih dan Sehat maupun tentang Limbah rumah tangga.

2. Mempersiapkan tempat untuk pelaksanaan pelatihan.

3. Membatu Melancarkan Kegiatan yang dilaksanakan

\section{Langkah Evaluasi}

Keberhasilan suatu kegiatan evaluasi akan dipengaruhi pula oleh keberhasilan evaluator dalam melaksanakan prosedur evaluasi. Prosedur tersebut adalah langkah- langkah pokok yang harus ditempuh dalam kegiatan evaluasi. 2Evaluasi yang akan dilakukan terdiri dari:

1. Evaluasi proses, yang terkait dengan perencanaan, pelaksanaan dan monitoring kegiatan. Evaluasi proses akan dilakukan setiap selesai perencanaan dan persiapan kegiatan.

2. Evaluasi hasil, yang akan dilaksanakan setelah kegiatan dilaksanakan. Evaluasi hasil ditujukan untuk mengetahui sejauh mana pemahaman masyarakat dalam menerima materi dan penggunaan pemanfaatan alat.

3. Evaluasi dampak, yang akan dilakukan setelah pelaksanaan pembinaan. Evaluasi dampak diarahkan untuk melihat efektivitas model pembinaan dan keberlangsungan penggunaaan alat pengolahan limbah an-organik. 


\section{REALISASI PROGRAM}

\section{Program Bidang Pendidikan}

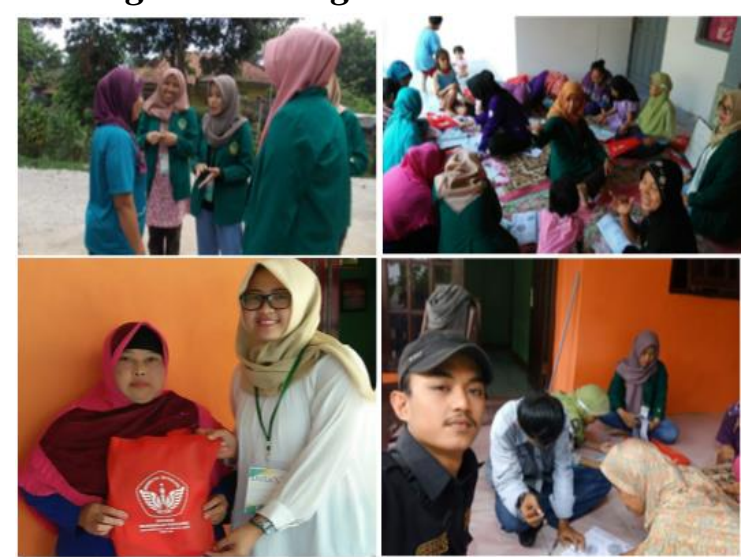

a. KF (Keaksaraan Fungsional)

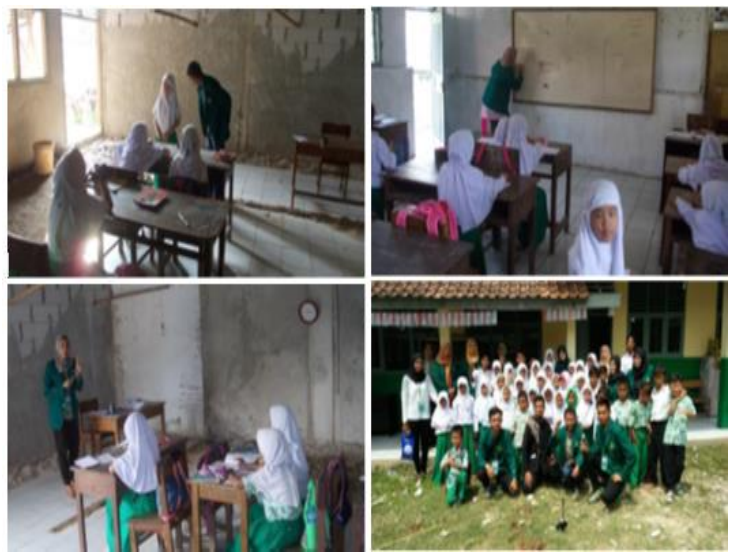

b. Partisipasi mengajar di Sekolah
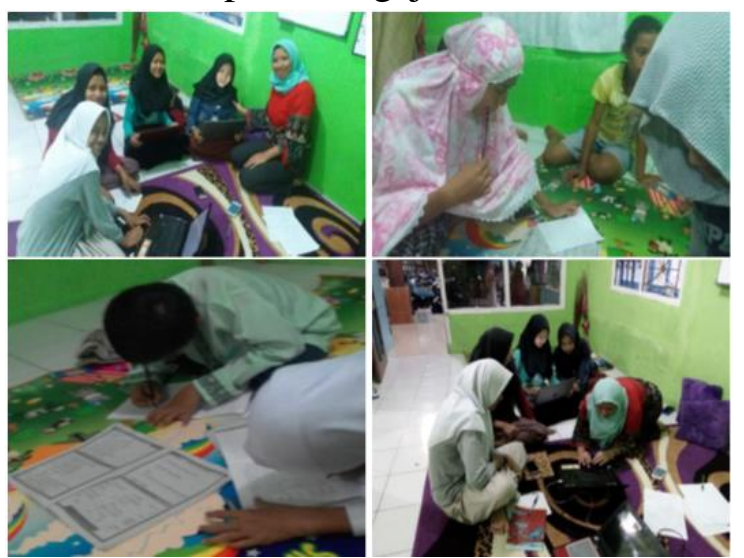

c. Bimbel

Tujuan : Agar masyarakat melek aksara, khususnya pada usia tua. Serta agar ilmu yang kita miliki bisa bermanfaat bagi warga sekitar, dan warga menjdapat manfaat dari apa yang telah di berikn atau di ajarkan.

\section{Program Bidang Lingkungan}

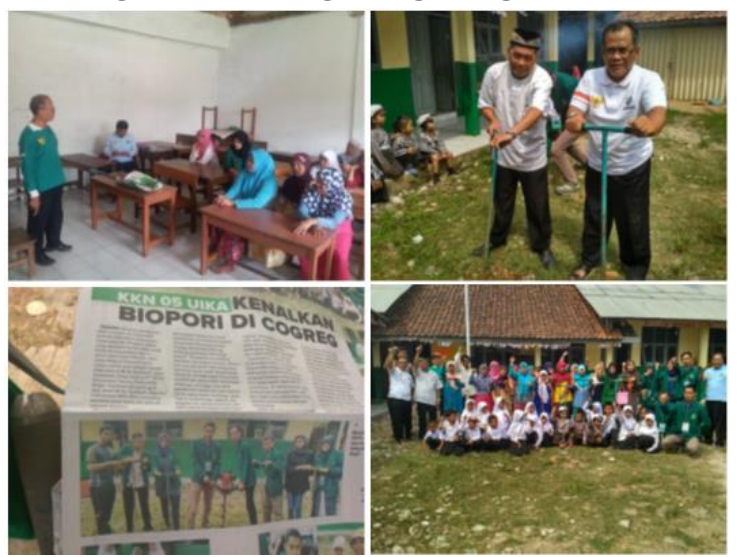

a. Biopori

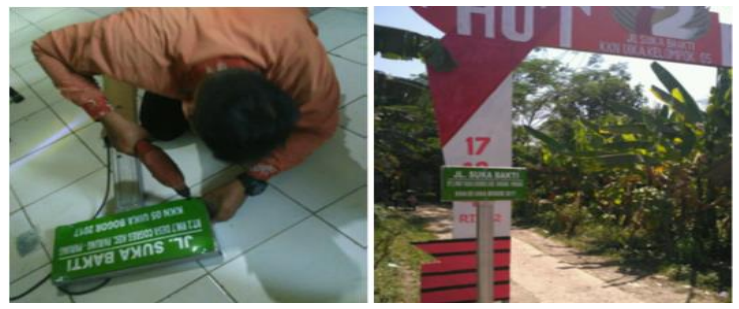

b. Plang Nama Jalan

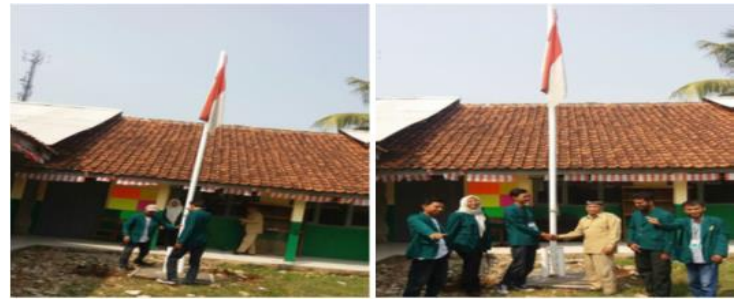

c. Tiang bendera

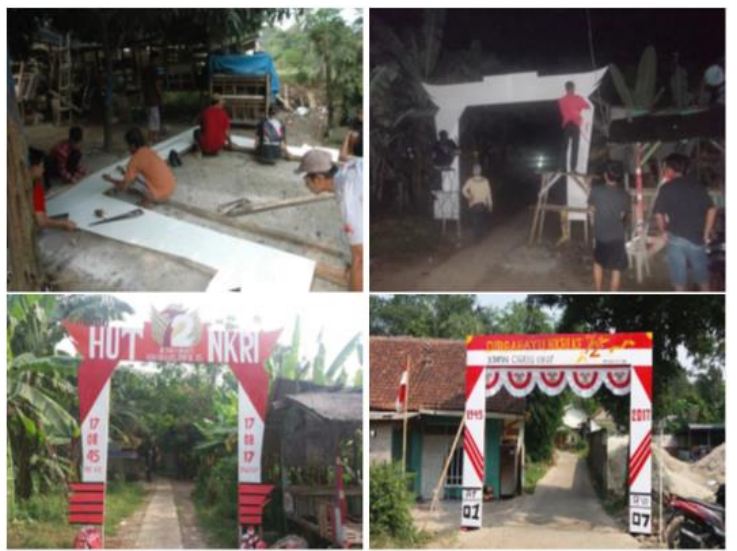

d. Gapura

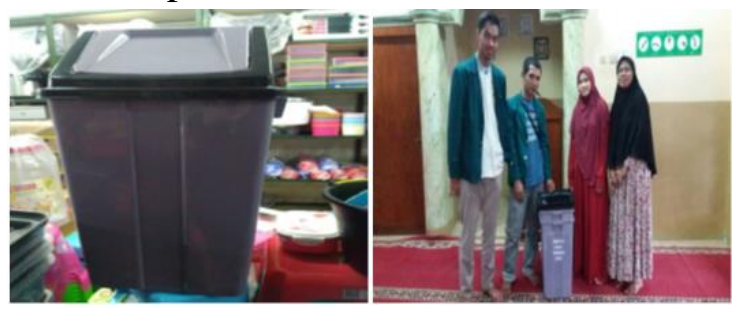

e. Pengadaan tempat sampah

f. Penanaman Pohon 
g. Budi daya cacing

Tujuan : Agar masyarakat dapat mengetahui mengenai BIOPORI, pentingnya keberadaan pohon-pohon di lingkungan kita, menyadari bahwa kebersihan itu suatu kebutuhan kita dan memmfasilitasi apa yang di butuhkan.

\section{Program Bidang Ekonomi}

a. Kantin Kejujuran

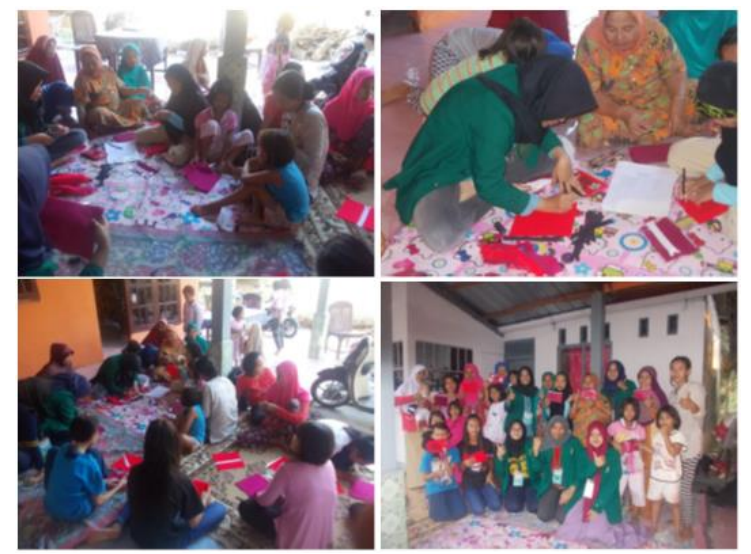

b. Kerajinan tangan

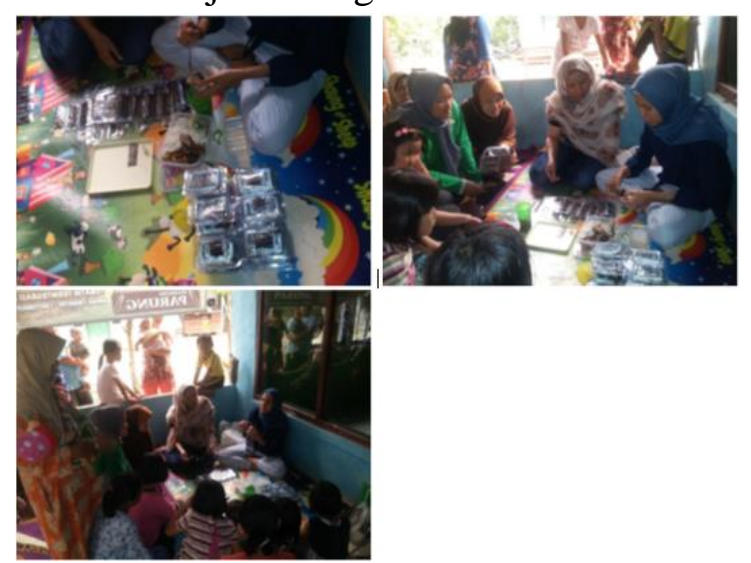

c. Demo Makanan (membuat Sushi Lele)

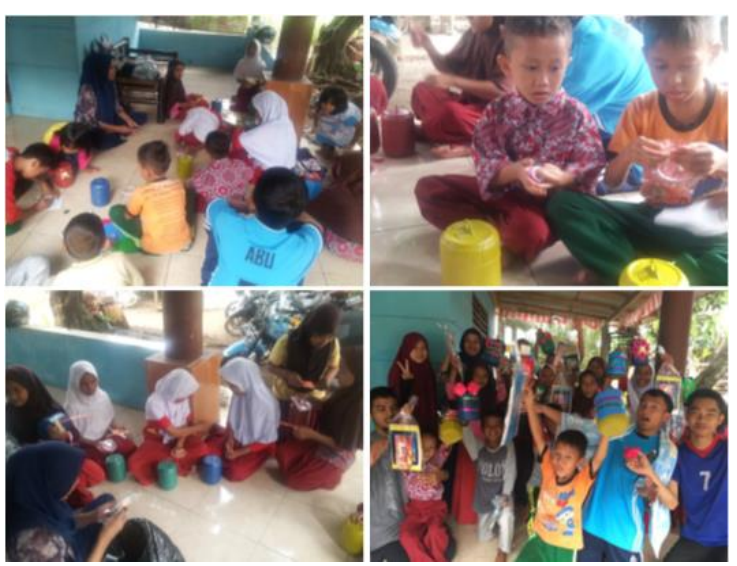

d. Menumbuhkan Budaya Menabung melalui Menghias Celengan

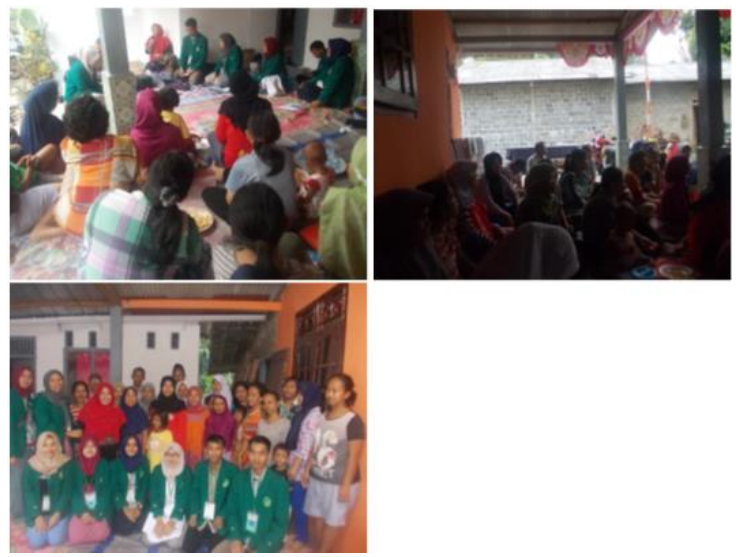

e. Seminar Usaha Mikro

Tujuan : Agar masyarakat memliki keterampilan dan bisa lebih berinovasi dalam menjalankan usaha dari keterampilan yang di miliki dan dari keelbihan yang ada pada lingkungannya atau kondisi yang ada di lingkungannya. Serta mengetahui ilmu mengenai usaha mikro sehingga ketika masyarakan memiliki suatu usaha bisa lebih produktif. 


\section{Program Bidang Kesehatan}

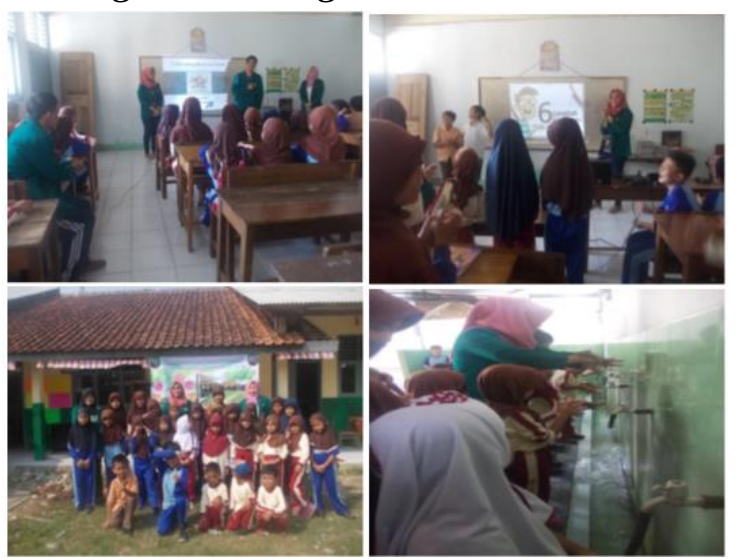

a. PHBS (Perilaku Hidup Sehat dan Bersih)

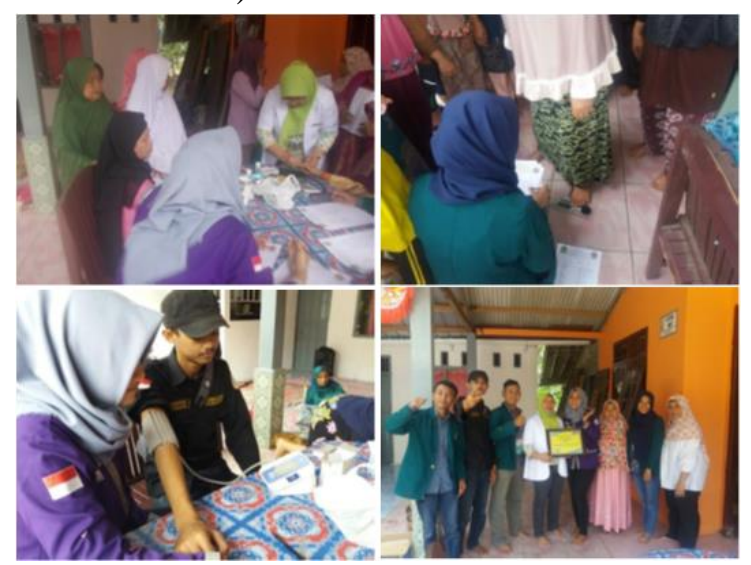

b. Pemeriksaan kesehatan gratis untuk masyarakat
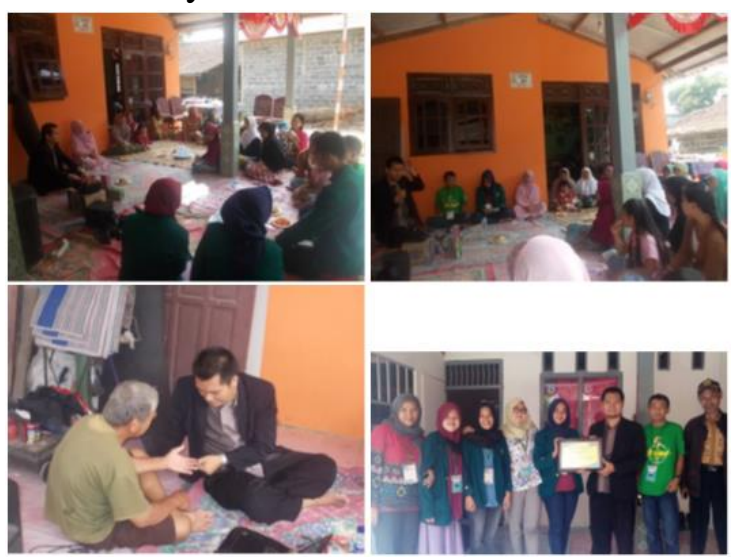

c. Seminar HPAI (Herbal Penawar AlWahidah Indonesia)

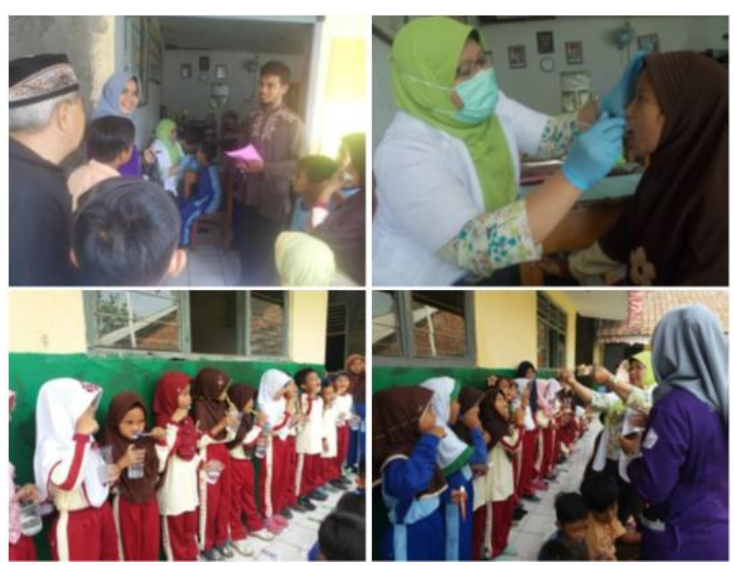

d. Penyuluhan Sikat Gigi yang baik dan benar

Tujuan : Agar masyarakat memiliki pola hidup bersih dan sehat, menyadari akan pentingnya kesehatan dan bagaimana menjaganya, serta mengetahui mengenai Herbal yang tak banyak orang konsumsi.

\section{Program Bidang Agama}

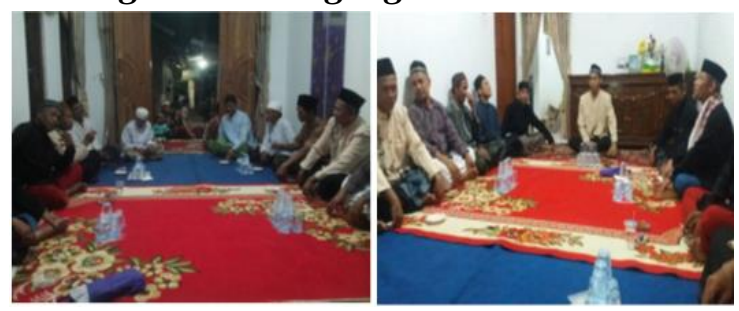

a. Pengajian Bapak-bapak

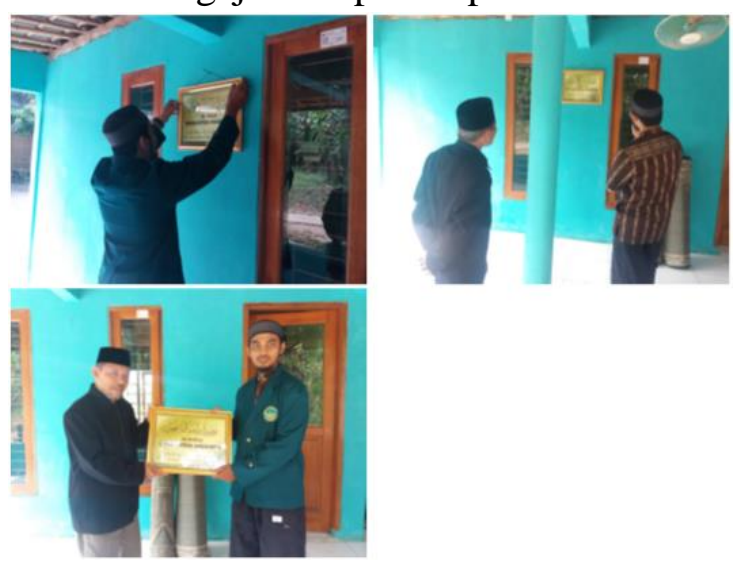

b. Papan Nama Mushala 


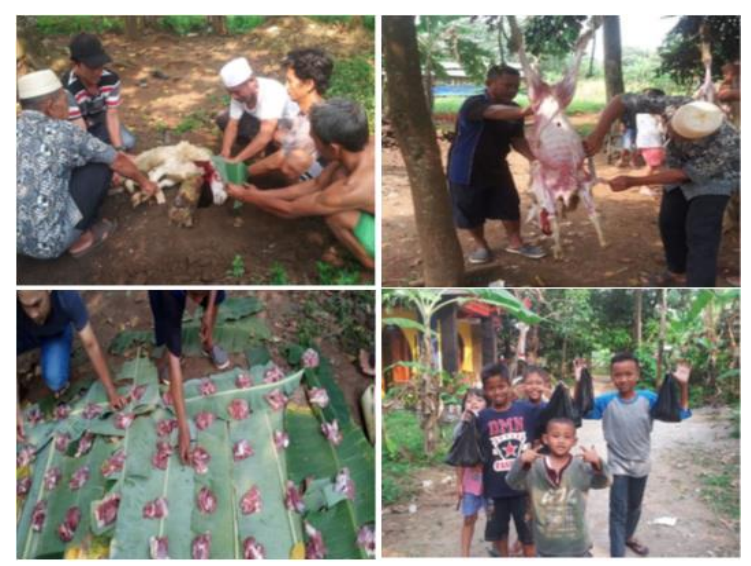

c. Qurban

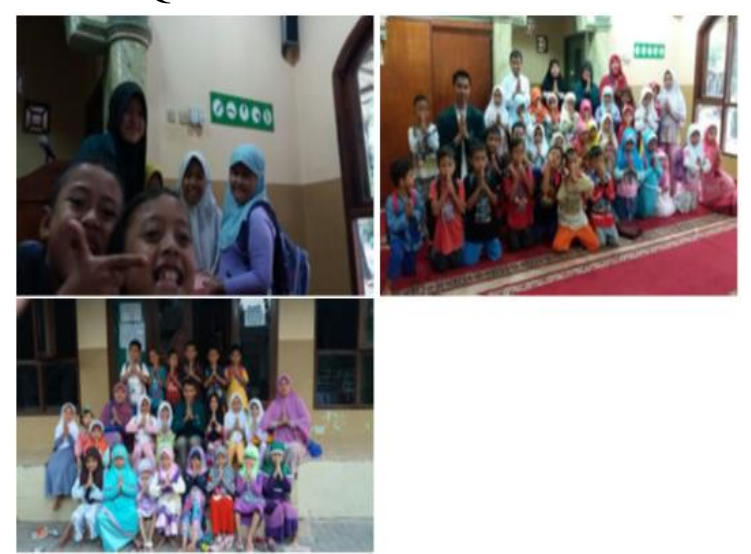

d. PAUD

e. TAUD
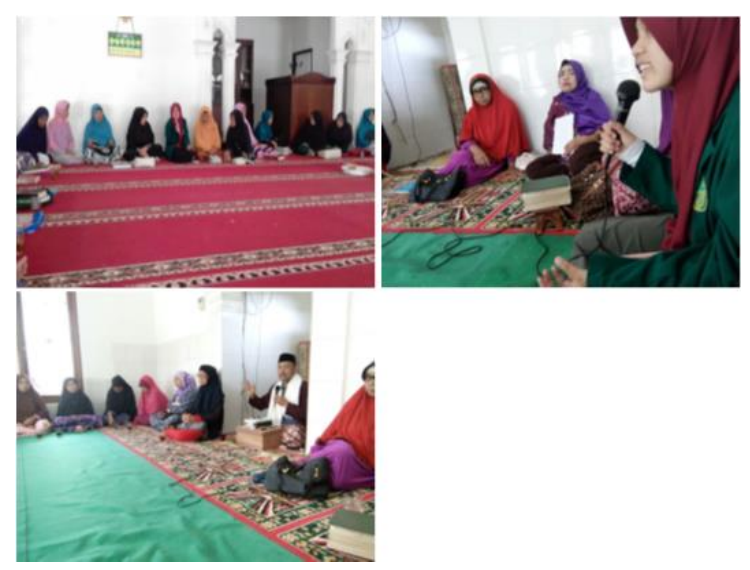

f. Pengajian Ibu-ibu

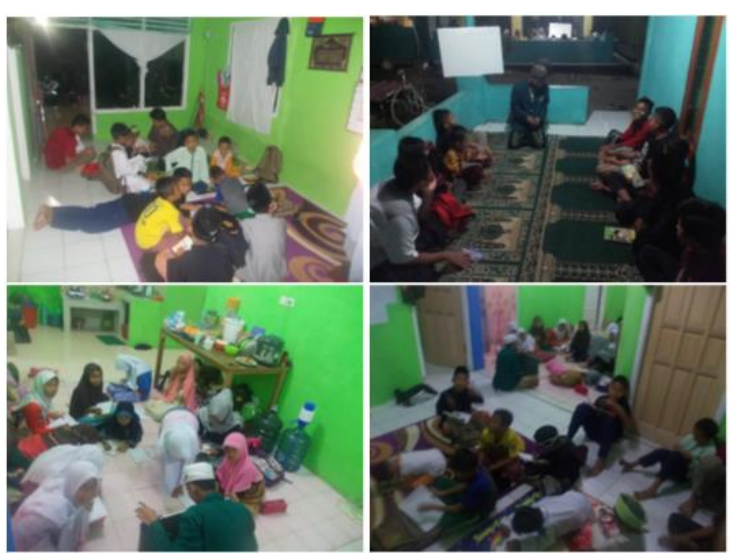

g. Pengajian Anak-anak

h. Pengajian Pemudi

Tujuan : Agar ilmu yang telah mahasiswa dapatkan baik selama belajar saat perkuliahan ataupun di luar perkuliahan dapat bermanfaat untuk masyarakat sekitar, serta masyarakat sekita dapat mengetahui ilmu-ilmu yang khususnya ilmu Agama.

\section{Kegiatan Lain-Lain}

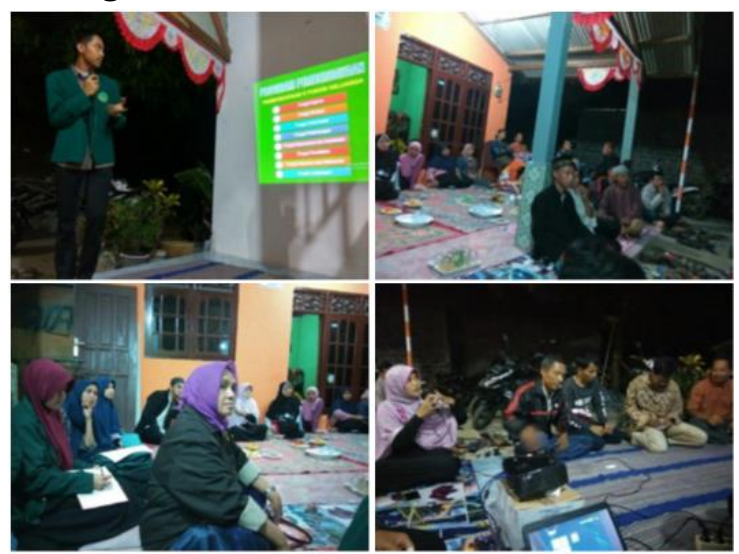

a. Pembentukan POSDAYA

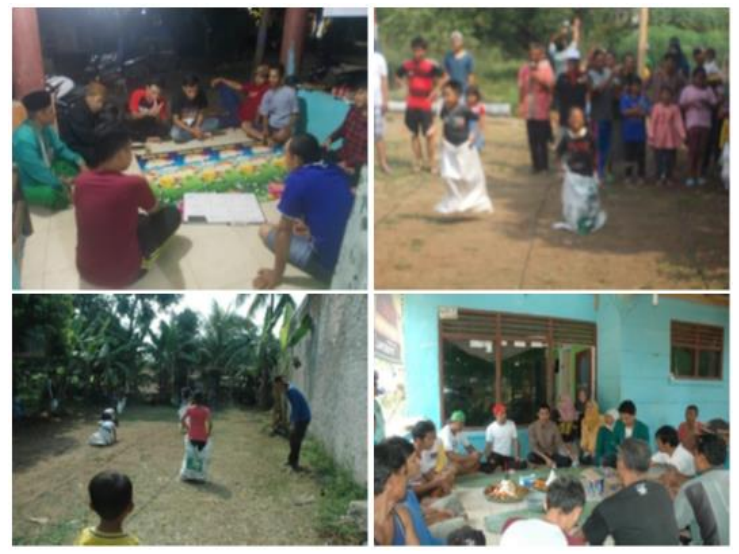

b. Peringatan HUT RI 

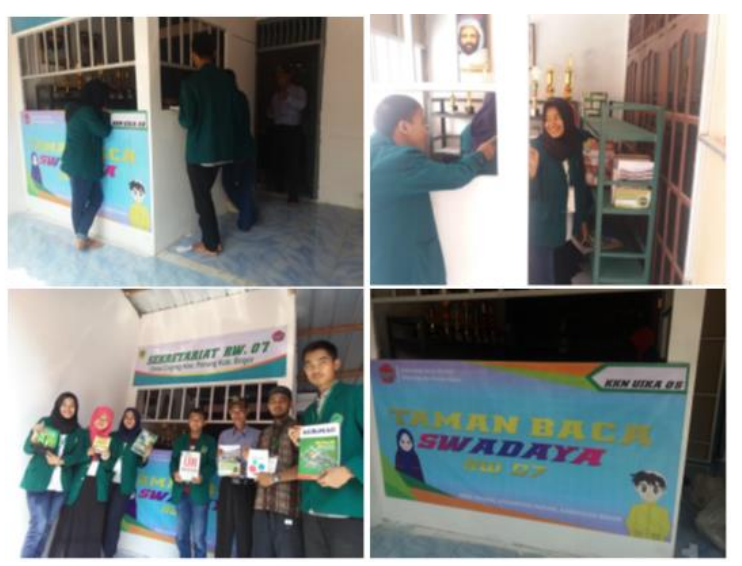

c. Taman Baca

\section{KESIMPULAN}

Berdasarkan kegiatan yang kami programkan dan laksanakan maka kami sebagai penyusun mengambil kesimpulan dari kelima bidang yang telah kami laksanakan yaitu dibidang pendidikan, kesehatan, ekonomi, hukum, dan teknologi. Dari kelima bidang tersebut secara keseluruhan semua bidang masih mempunyai permasalahan yang harus ditangani, mulai dari bidang pendidikan, yaitu kurangnya pengetahuan tentang ilmu pendidikan.

Dibidang Kesehatan Desa Kuripan masih mempunyai masalah kesehatan, Karena kondisi lingkungan yang kurang bersih dan sehat. Di bidang ekonomi masyarakat sekitar masih mempunyai masalah keuangan yang seharusnya bisa ditangani dengan usaha mandiri oleh warga dengan memanfaatkan sumber daya alam yang banyak tersedia di daerah tersebut.

Dibidang Teknologi masyarakat belum sepenuhnya mengenal teknologi tarapan, teknologi ini dapat membantu masyarat untuk mengelola limbah rumah tangga. Dengan berbagai permasalahan yang ada kami Mahasiswa KKN (Kuliah Kerja Nyata) mencoba membantu masyarakat sekitar dan masyarakat menerima kami dengan sangat baik. Tidak banyak halangan yang kami hadapi kecuali datangnya dari diri kami sendiri. Oleh karena itu, Kegiatan KKN yang kami laksanakan di Desa Kuripan ini berjalan dengan baik.

Dampak Bagi Masyarakat dari semua program yang Kami Laksanakan adalah

1. Meningkatnya pengetahuan Masyarakat dari penyuluhan yang diberikan oleh mahasiswa, terkait penyuluhan tentang kesehatan, ekonomi, hukum tentang narkoba maupun keagamaan.

2. Dari Segi kesehatan, masyarakat mempu untuk merubah perilakunya agar hidup bersih dan sehat.

3. Dari Segi Ekonomi, Mahasiswa Memperkenalkan sebuah produk makanan berbahan dasar daun singkong. Masyarakat mampu mengembangkan produk ini agar mendapat penghasilan tambahan, dan juga memanfaatkan daun singkong yang banyak terdapat di RW 04.

4. Dari pelatihan pemanfaatan sampah rumah tangga, masyarakat mampu mengaplikasikannya seperti pembuatan Bahan Bakar Minyak dari sampah plasik, dan juga pembuatan gelas dari botol kaca bekas yang nantinya jika di hias dengan cara dilukis bisa menjadi souvenir dan menjadikan Dusun Cihowe Ombang menjadi Pusat Pengerajin souvenir Gelas

\section{SARAN}

\section{a. Pemerintahan Kabupaten/Provinsi}

Pemerintah Kabupaten/Provinsi agar lebih memperhatikan kepentingan dan keperluan pelayanan masyarakat yang ada di wilayah Pedesaan. 


\section{b. Pemerintahan desa/ Kecamatan}

Potensi-potensi yang ada di masyarakat yang sudah terbina dan berjalan dengan baik agar terus dipertahankan dan di kembangkan.

\section{c. Pemerintah Desa}

1. Agar lebih banyak memberikan kesempatan kepada masyarakat untuk berperan aktif dalam pelaksanaan pembangunan di Desa Kuripan

2. Dapat memanfaatkan potensi-potensi yang ada di wilayah Desa untuk kepentingan bersama.

3. Mempertahankan kualitas dan kuantitas Desa Kuripan

4. Agar terus membina masyarakat untuk berperan aktif dalam pengembangan pembangunan Desa.

\section{REFERENSI}

Administrasi Profil Desa Kuripan

Arifin, Zainal. 2011. Evaluasi Pembelajaran. Bandung: PT Remaja Rosdakarya

Bahari. (2010). Toleransi Beragama Mahasiswa (Studi tentang Pengaruh Kepribadian, Keterlibatan Organisasi, Hasil Belajar Pendidikan Agama, dan Lingkungan Pendidikan terhadap Toleransi Mahasiswa Berbeda Agama pada 7 Perguruan Tinggi Umum Negeri. Jakarta: Kementerian Agama RI Badan Litbang dan Diklat Puslitbang Kehidupan Keagamaan.

Eska Perdana Prasetya (2016), The Effect of Students' Perception on School Environment and Self-discipline towards Their Achievement in Learning English: A Survey at a Private Vocational School in Bogor

Joyce, Bruce dan Weil, Marsha. (1996). Models of Teaching. Boston: Allyn and Bacon

Munandar Soelaeman. 2009. Ilmu Sosial Dasar. Bandung: refika aditama.

Petunjuk Pelaksanaan KKN Tematik Terintegrasi 2017 Universitas Ibn Khaldun Bogor

Rachmawati, AFD. (2006). Toleransi Antar Umat Islam dan Katolik: Studi Kasus di Dukuh Kasaran, Desa Pasungan, Kecamatan Ceper, Kabupaten Klaten. Skripsi. Semarang: IAIN Walisongo.

Slavin, R.E. (2005). Cooperative learning: theory, research and practice. London: Allyn and Bacon. 